\title{
Effect of Dilution on the Microstructure and Properties of CoCrMoSi alloy Coatings Processed on High-Carbon Substrate
}

\author{
Karin Graf $f^{u}$ Ulrich Tetzlaff ${ }^{b}$, Gelson Biscaia de Souzac, Adriano Scheid ${ }^{a, *}$ (i) \\ ${ }^{a}$ Departamento de Engenharia Mecânica - DEMEC, Universidade Federal do Paraná, Av. Cel. \\ Francisco H. dos Santos, 210, Curitiba, PR, Brasil \\ ${ }^{b}$ Department of Materials Engineering, Technische Hochschule Ingolstadt - THI, Esplanade, 10, \\ Ingolstadt, Germany \\ ${ }^{c}$ Departamento de Física, Universidade Estadual de Ponta Grossa - UEPG, Av. Gen. Carlos Cavalcanti, \\ 4748, Ponta Grossa, PR, Brasil
}

Received: July 16, 2018; Revised: October 08, 2018; Accepted: October 25, 2018

\begin{abstract}
The Laves phase reinforced CoCrMoSi alloy system has emerged as a candidate material to protect the surface of components to withstand harsh environments under wear and/or corrosion. However, previous reports have raised some concerns and restricted a wider selection of iron-based substrates to be coated, especially limiting the carbon content. This work aims to outline the Laves - Carbides phases in the microstructure and its effect on the properties of T400 alloy deposited on GGG40 ductile iron. Dilution of $26 \%$ ensured Laves formation either as primary or secondary, due to high-silicon substrate selected. Departing from $41 \%$ dilution, the alloy changed to a completely carbide strengthened system. Therefore, for the lowest dilution the coatings hardness is dictated by Laves phase whereas, for higher ones, carbides are the most influent phases.
\end{abstract}

Keywords: CoCrMoSi Alloy, Microstructure, Coatings, High-Carbon Substrate.

\section{Introduction}

The demand for extending the useful life of mechanical components has been a challenge for engineers, especially when the operating condition involves wear, corrosion, or both simultaneously. Hardfacing presents itself as a good alternative to protect the surface for specific applications, since it addresses particular issues related to wear mechanisms such as adhesion or abrasion, which are often associated with corrosive media ${ }^{1}$. Surface wear resistance may be substantially improved by depositing a wear resistant material through a welding process ${ }^{2}$. Therefore, the selected feeding material, substrate and processing parameters emerge as decisive on the microstructure and hardness of the resulting coating and, thus, its wear behavior ${ }^{1}$.

As a welding technique to produce hard coatings, Plasma Transferred Arc with powder feeder (PTA-P) has being widely employed. The powder feeding material produces refining microstructures and also enables a modifiable chemical composition of the coatings. PTA-P has many advantages, such as metallurgical bonding, dilution control, low penetration, reduced melting pool oscillations and no spray, good control of the geometry and surface finishing of the processed layers ${ }^{3,4}$.

The most broadly adopted surfacing alloys are highcarbon/chromium iron-based alloys, chromium-graphite mixtures, iron-based alloys enriched by niobium, titanium, molybdenum and/or boron and nickel and cobalt-based alloys. The latter are recognized for their excellent wear and corrosion properties, high strength and ability to retain hardness at high temperatures ${ }^{1}$.

The CoCrMoSi alloy system exhibits excellent wear resistance that relies on a large percentage of the Laves hard intermetallic phase (CoMoSi and/or $\mathrm{Co}_{3} \mathrm{Mo}_{2} \mathrm{Si}$ ). In this system, Laves is usually a primary phase dispersed in a lamellar eutectic structure that comprises cobalt solid solution (Co-SS) and secondary Laves phase lamellas. This typical microstructure is developed in the commercially known Tribaloys, as T800 and T400 ${ }^{5-10}$. It should be noted that T400 alloy was designed with a lower amount of chromium and silicon compared to T800 for higher ductility and toughness through reducing primary Laves phase formation up to $50 \%{ }^{7-9}$.

As Tavakoli et al. ${ }^{7}$ suggest, an advantage of tribaloy alloys over carbide-reinforced Co-based ones is that the Laves phase is softer (hardness about half) than the carbides, the latter wearing away sometimes a mating surface. For this reason, the carbon content in tribaloy alloys is kept low to prevent carbides forming in preference to the Laves phase ${ }^{7}$. It can also justify the fact that microstructure and mechanical properties of CoCrMoSi alloys have been extensively studied as coatings on low-Carbon AISI 316L stainless steel substrate ${ }^{11-16}$. As a result, however, there is limited information about processing of these complex alloys on low-cost high-carbon content substrates such as cast irons (Fe-C-Si alloys).

Many studies have being carried out to improve corrosion and wear resistance selecting Ni-based alloys, ${ }^{17-20}$, TiC-W$\mathrm{Cr}$ alloying ${ }^{21}$, and in situ precipitation of $\mathrm{TiC}^{22}$ on gray cast 
irons. Despite showing the effect of iron additions on the Tribaloys T400 and T800 microstructure and properties ${ }^{23-25}$, there is an evident gap concerning the effect of processing CoCrMoSi alloys coatings on Fe-C-Si alloy substrates. Hence, the aim of this investigation is to evaluate the effect of simultaneous introduction of iron, carbon and silicon (due to welding dilution) on the microstructure and properties of the Co base T400 alloy coatings processed by PTA on highcarbon content GGG40 ductile Iron. Emphasis was given to outline the expected phase competition in the microstructure (Laves / carbides) and its effect on the properties of coatings.

\section{Materials and Methods}

CoMoCrSi alloy, commercially known as Tribaloy T400, with particle size ranging between $50-150 \mu \mathrm{m}$, was deposited on ductile iron (GGG40) substrate, as shown in Table 1.

In this work, the main objective was to investigate the effect of dilution with the substrate on the microstructure and properties of the coatings. Thus, to promote distinct dilution, coatings were prepared by PTA-P as single beads with four distinct deposition currents: 120,150, 180 and $200 \mathrm{~A}$. The procedure is in agreement with previous experience and results presented in the literature for such an approach ${ }^{11,13,24,26-28}$. Table 2 shows the main deposition parameters utilized.

Single bead specimens were cut on a transversal cross section for metallographic analysis according to standard procedures, which involved grinding and polishing. Coatings were also characterized according to their bead geometry (height, width and wettability), and dilution was assessed by areas method $24,26-28$.

X-ray diffraction (XRD) analysis was carried out on the top surface of coatings with $\mathrm{K}_{\alpha}$ Co radiation ranging from 30 to $120^{\circ}$ for phase identification. Microstructure was analyzed by scanning electron microscopy (SEM) on the transversal cross section of the deposits.

The effect of dilution on coatings mechanical properties was assessed by hardness Rockwell C. Further analysis of the microstructure phases hardness involved instrumented indentation method (MTS Nanoindenter XP) carried out in 110 different sites with cycling loads of $20 \mathrm{mN}$. Moreover, coatings were scratched under $100 \mathrm{mN}$ constant load. The indentation imprints and scratches width produced with a Berkovich-type diamond tip in the specimens transverse cross-section were examined through backscattered electrons (BSE) in a SEM (TESCAN $\left.{ }^{\mathrm{TM}}\right)$, as seen in Fig. 1.
Table 2. Processing parameters

\begin{tabular}{lc}
\hline Parameter & Value \\
\hline Plasma gas (1/min) & 2 \\
Protection gas $(1 / \mathrm{min})$ & 15 \\
Powder feeding gas $(1 / \mathrm{min})$ & 2 \\
Main arc current $(\mathrm{A})$ & $120,150,180$ and 200 \\
Powder feed rate & Constant in volume \\
Travel speed (mm/min) & 100 \\
Torch/Substrate distance $(\mathrm{mm})$ & 10 \\
Electrode diameter $(\mathrm{mm})$ & 3.125 \\
\hline
\end{tabular}

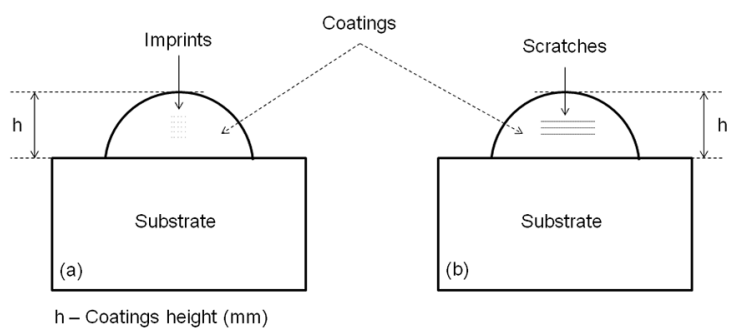

Figure 1. Schematic placing of instrumented indentation tests.

\section{Results}

\subsection{Coatings dilution and geometry}

As expected, single bead coatings of $100 \mathrm{~mm}$ in length revealed no welding defects such as cracks, undercut, under fill or porosities. As the current intensity increased along width and wettability, the height of the layers decreased. It was observed that the higher the heat input (higher current intensity) was, the higher was dilution, as shown in Table 3.

\subsection{Microstructure description}

XRD analysis indicated predominance of cobalt solid solution (Co-SS) and Laves phase (CoMoSi and $\mathrm{Co}_{3} \mathrm{Mo}_{2} \mathrm{Si}$ ) in the microstructure for coatings processed with $120 \mathrm{~A}$ (26\% dilution). As the deposition current increases (dilution between 41 and 50\%), Laves was completely suppressed and carbides formed preferentially to the Laves phase, as can be seen in Fig. 2. Table 4 presents a summary of the different phases.

Fig. 3a-d shows a general view of the microstructure observed with SEM in the backscattered electrons mode (BSE) for the specimens. As the deposition current increases, it is clear that lighter phase (primary) gradually decreases.

Table 1. Chemical composition of the materials studied (weight percent)

\begin{tabular}{lcccccc}
\hline Alloy & Fe & Co & Mo & Cr & Si & C \\
\hline $\begin{array}{l}\text { CoCrMoSi } \\
\text { (Tribaloy T400) }\end{array}$ & 0.4 & Bal. & 29.1 & 8.8 & 2.4 & $<0.1$ \\
\hline Substrate & $\mathbf{F e}$ & $\mathbf{S i}$ & $\mathbf{C}$ & $\mathbf{M n}$ & $\mathbf{P}_{\text {max. }}$ & $\mathbf{S}_{\text {max. }}$ \\
\hline $\begin{array}{l}\text { Ductile Iron } \\
\text { (GGG40) }\end{array}$ & Bal. & 2.8 & 3.9 & 0.2 & 0.04 & 0.02 \\
\hline
\end{tabular}


Table 3. Dilution and geometry of single bead coatings

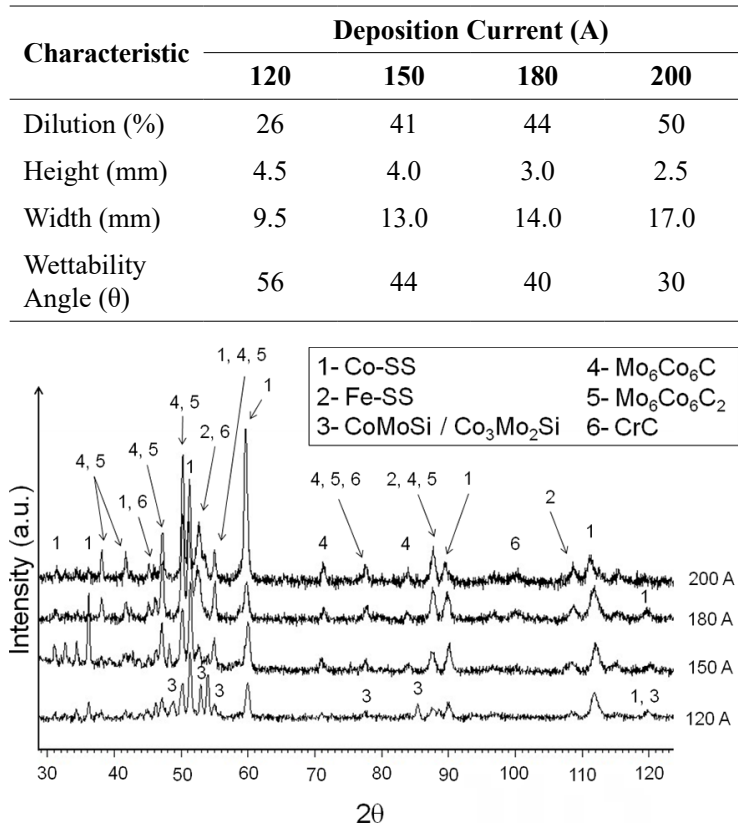

Figure 2. XRD diffractograms for the conditions evaluated.

Table 4. Summary of the main phases

\begin{tabular}{|c|c|c|}
\hline \multirow{2}{*}{$\begin{array}{c}\text { Deposition } \\
\text { Current } \\
\text { (A) }\end{array}$} & \multicolumn{2}{|c|}{ Main Phases } \\
\hline & Primary Phases & Eutectic \\
\hline 120 & $\begin{array}{l}\mathrm{CoMoSi} / \mathrm{Co}_{3} \mathrm{Mo}_{2} \mathrm{Si}+ \\
\mathrm{Co}_{6} \mathrm{Mo}_{6} \mathrm{C} / \mathrm{Co}_{6} \mathrm{Mo}_{6} \mathrm{C}_{2}\end{array}$ & $\begin{array}{c}\mathrm{Co}-\mathrm{SS}+\mathrm{CoMoSi} / \\
\mathrm{Co}_{3} \mathrm{Mo}_{2} \mathrm{Si}\end{array}$ \\
\hline 150 & $\mathrm{Co}_{6} \mathrm{Mo}_{6} \mathrm{C} / \mathrm{Co}_{6} \mathrm{Mo}_{6} \mathrm{C}_{2}$ & $\begin{array}{c}\mathrm{Co}-\mathrm{SS}+\mathrm{Co}_{6} \mathrm{Mo}_{6} \mathrm{C} \\
/ \mathrm{Co}_{6} \mathrm{Mo}_{6} \mathrm{C}_{2}\end{array}$ \\
\hline 180 & $\mathrm{Co}_{6} \mathrm{Mo}_{6} \mathrm{C} / \mathrm{Co}_{6} \mathrm{Mo}_{6} \mathrm{C}_{2}$ & $\begin{array}{c}\mathrm{Co}-\mathrm{SS}+\mathrm{Co}_{6} \mathrm{Mo}_{6} \mathrm{C} \\
/ \mathrm{Co}_{6} \mathrm{Mo}_{6} \mathrm{C}_{2}\end{array}$ \\
\hline 200 & No primary phase & $\begin{array}{c}\mathrm{Fe}-\mathrm{SS}+\mathrm{Co}_{6} \mathrm{Mo}_{6} \mathrm{C} / \\
\mathrm{Co}_{6} \mathrm{Mo}_{6} \mathrm{C}_{2}\end{array}$ \\
\hline
\end{tabular}
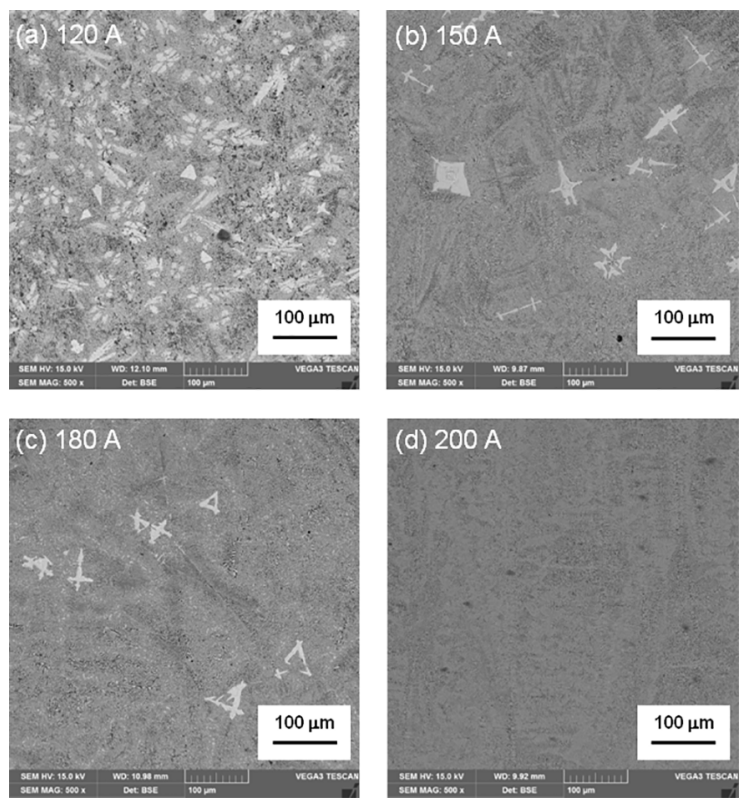

Figs. 4- 7show the detailed microstructure of the coatings. Fig. 4a-b shows that the lighter phase is comprised of primary Laves phase (CoMoSi / $\mathrm{Co}_{3} \mathrm{Mo}_{2} \mathrm{Si}$ ) and primary edged carbide. Moreover, the microstructure showed a lamellar eutectic structure with Co-SS and secondary Laves phase. It is important to highlight that surrounding the primary phases; the composition was depleted in molybdenum inducing a local hypoeutectic solidification with Co-SS dendrites (Fig. 4b).

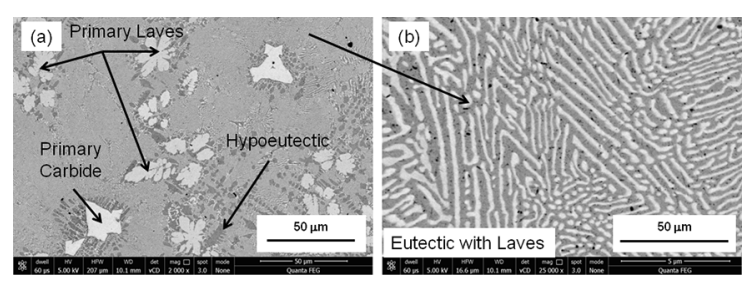

Figure 4. Detailed coatings microstructure deposited with $120 \mathrm{~A}$.

Fig. 5a-b shows the detailed microstructure for specimens deposited with 150 A main current. The suppression of the Laves phase occurred, either as primary or secondary in the eutectic. The microstructure was then comprised of primary carbides in a labyrinth-like lamellar eutectic microstructure containing cobalt solid solution (Co-SS) and carbides $\left(\mathrm{Co}_{6} \mathrm{Mo}_{6} \mathrm{C}_{2} / \mathrm{Co}_{6} \mathrm{Mo}_{6} \mathrm{C}\right)$.

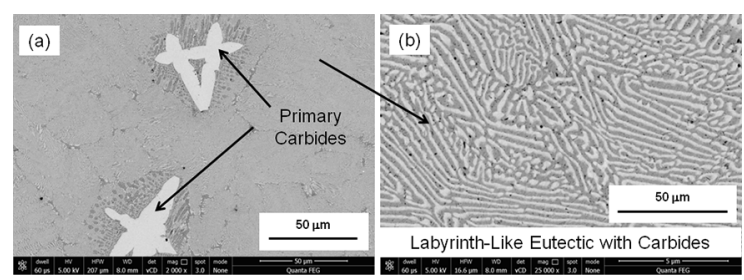

Figure 5. Detailed coatings microstructure deposited with $150 \mathrm{~A}$.

The further increase of the deposition current to 180 A induced the development of a microstructure comprised of primary carbides and lamellar eutectic microstructure, as seen in Fig. 6a-b. Analysis indicated that the increased dilution induced an increase in carbon and silicon content in the coatings, which in turn changed the eutectic morphology to skeleton-like carbides, consistent with previous work ${ }^{29}$.

Fig. 7a-b shows the detail of the microstructure for specimens processed with $200 \mathrm{~A}$. The increased interaction with the substrate resulted in a microstructure free of primary phase with predominance of skeleton-like eutectic carbides, containing iron solid solution (Fe-SS), which is associated with the measured $50 \%$ dilution.

\subsection{Mechanical properties}

Fig. 8 shows the mean hardness measured on the cross section of the coatings. Results initially indicated that an increase in dilution from $26(120 \mathrm{~A})$ to $41 \%(150 \mathrm{~A})$ induced a decrease in hardness. On the contrary to the normal trend

Figure 3. General view of the coatings microstructure. 
observed in several reports for coatings processing on lowcarbon iron-base alloys, hardness increased to even higher deposition currents.

Figs. 9-12 presents the SEM images of the nanoindentation and correspondent hardness values obtained for the different

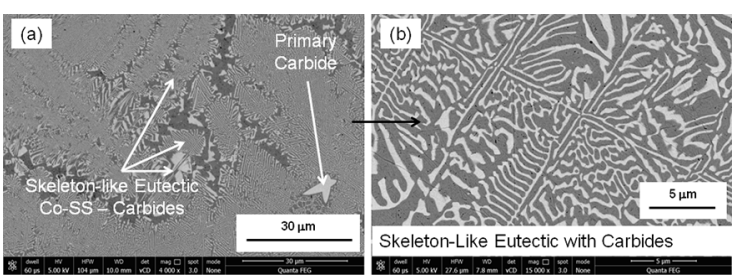

Figure 6. Detail of the microstructure deposited with $180 \mathrm{~A}$.

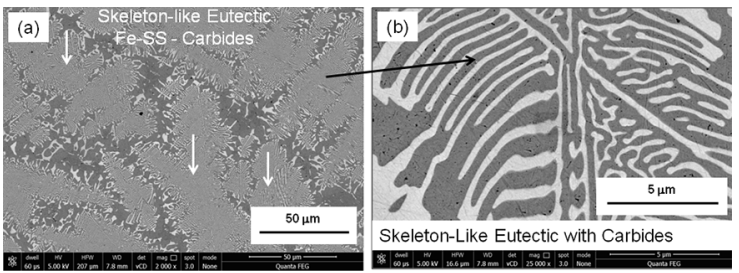

Figure 7. Detail of the microstructure deposited with $200 \mathrm{~A}$.

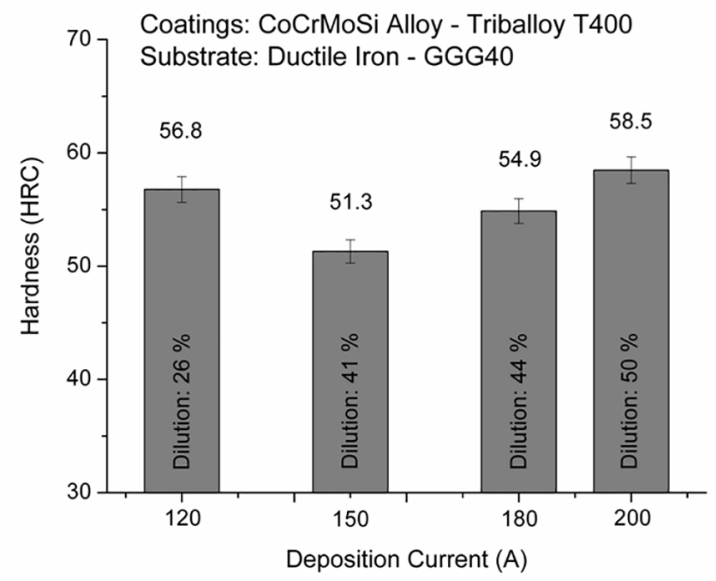

Figure 8. Hardness of the single bead specimens.
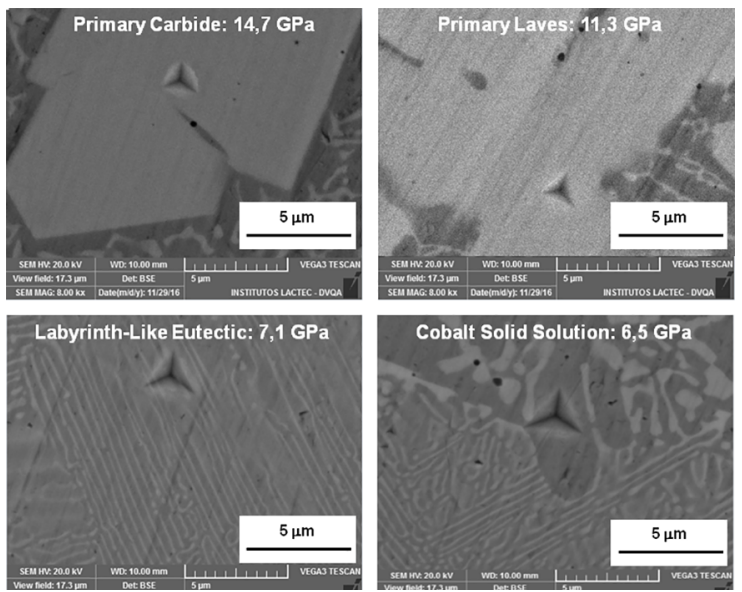

Figure 9. Typical hardness evaluation for microconstituents observed for the coatings - 120A.

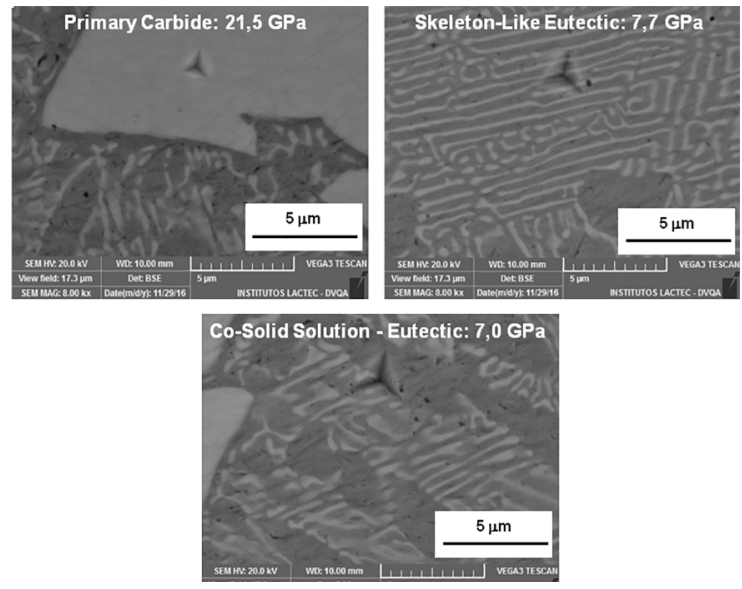

Figure 10. Typical hardness evaluation for microconstituents observed for the coatings - 150A.
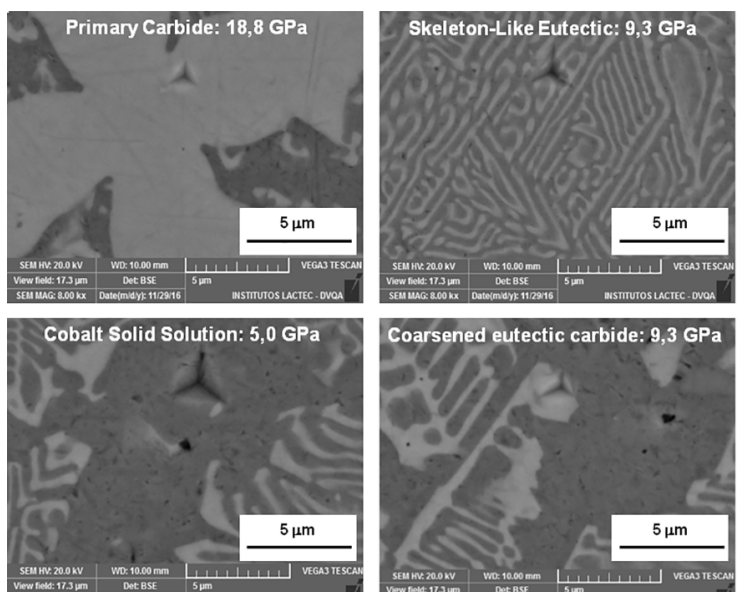

Figure 11. Typical hardness evaluation for microconstituents observed for the coatings - 180A.
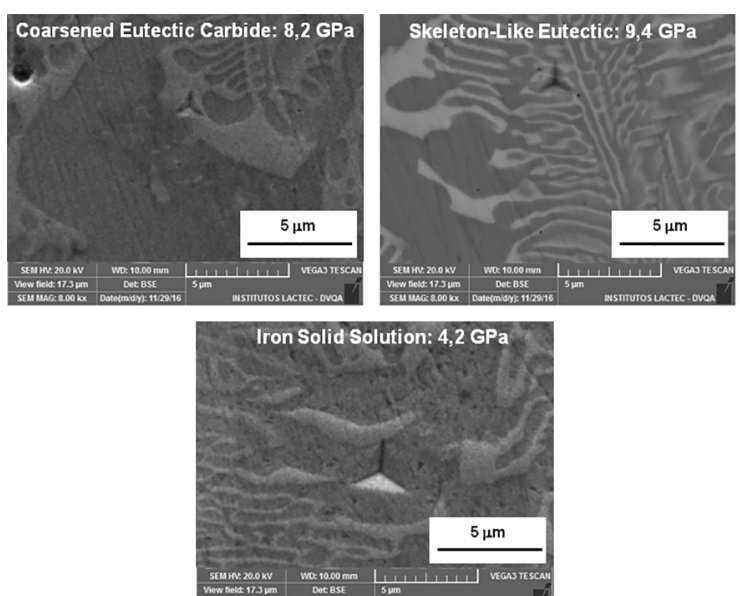

Figure 12. Typical hardness evaluation for microconstituents observed for the coatings - 200A.

phases in the aforementioned microstructure. Fig. 13 shows comparative images of the scratch tracks and confirms the unusual hardness due to the distinct phases in the microstructure. 

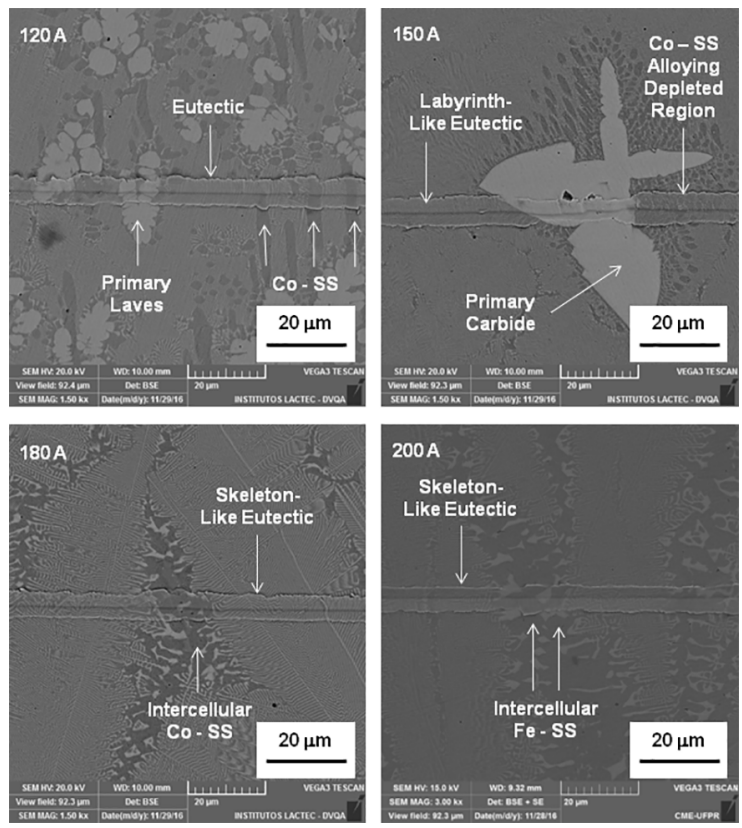

Figure 13. Typical Scratches on the microstructure of the coatings (Load: $100 \mathrm{mN}$ ).

\section{Discussion}

From Table 3, it is clear that the substrate effect on dilution of the coatings, i.e. the high values observed can be attributed to the cast iron substrate. Bohatch et al. ${ }^{25}$ evaluated the CoCrMoSi T400 alloy by PTA on AISI $316 \mathrm{~L}$ stainless steel and, despite the lower thermal conductivity of this substrate, lower dilution was obtained for the same deposition current intensities. Thus, an interesting finding concerning the influence of the substrate on dilution is that, since similar thickness and heat input was adopted, the differences in dilution can be associated with the chosen substrate melting point.

One of the main objectives of this work was to correlate dilution results (or simultaneous introduction of iron, carbon and silicon) to Laves formation. Therefore, one is compelled to also consider the effect of differences in the chemical composition that lead to the development of distinct phases in the coatings. A comparative approach of the XRD analysis indicated that Laves phase was only formed for the lowest deposition current, i.e. 120 A (see Fig. 2). Primary carbides were formed - even for the lowest dilutions - as a result of the chosen substrate, which contains a high carbon content.

In this work, for selected materials and processing conditions, the microstructure is governed by a competitive process which involved Laves and carbide phase formation. For the coatings deposited with $120 \mathrm{~A}$, the microstructure indicated two different primary phases embedded in an eutectic lamellar: Laves and carbides. Bohatch et al. ${ }^{24}$ notably found a completely eutectic microstructure for CoCrMoSi (T400) coatings with $18 \%$ dilution on AISI $316 \mathrm{~L}$ whereas, in this work, for a higher dilution level (26\%) on a ductile iron substrate, the Laves phase remains as primary as well as in the eutectic. Furthermore, previous works pointed out that Laves phase fraction is directly controlled by molybdenum and silicon contents $9,10,24$. According $\mathrm{Xu}$ et al. ${ }^{9}$, the CoCrMoSi T401 alloy was designed with lower molybdenum (22 $\mathrm{wt} \%)$ and silicon $(1.2 \mathrm{wt} \%)$ and showed hypoeutectic microstructure comprised of primary Co-SS and secondary Laves in the eutectic. Therefore, it is reasonably that the microstructure remained hypereutectic in this study as a consequence of the ductile Iron selected as the substrate (with $2.8 \mathrm{wt} \% \mathrm{Si}$ ), concomitantly introducing silicon, iron and carbon. Therefore, despite lower molybdenum content (as a consequence of dilution), silicon was not reduced, which in turn ensured primary Laves formation.

Further increase in current deposition for 150 and $180 \mathrm{~A}$ changed the composition of melting pool to a carbide alloy system, either as a primary or as a secondary carbides phase in the eutectic microstructure, suppressing Laves phase (see Figs. 5 and 6). In this case, the higher carbon content became determinant on phase development. It is interesting to notice that eutectic carbides morphology were also altered, showing a labyrinth-like eutectic for $150 \mathrm{~A}$, and changing to skeleton-like carbide eutectic for $180 \mathrm{~A}$. It was definitely a result of a higher carbon and silicon content, the latter being the one responsible for morphology differences as previously reported in the literature ${ }^{29}$.

Finally, the suppression of the primary carbides occurred by increasing the dilution to $50 \%$ (200 A), which resulted in a full skeleton-like carbides eutectic structure (Fig. 7). Further iron introduction in the chemical composition was able to displace the hypereutectic composition to a full eutectic carbides system (see Fig. 4d).

After outlining the effect of dilution on the microstructure, its effect on the mechanical behavior of coatings could be assessed. As dilution increases, a higher content of iron (major element in the substrate) tends to reduce molybdenum and chromium alloying and, at the same time, increase the amount of carbon and silicon. Thus, the effect of the primary Laves suppression is more straightforward; that is, the decrease in hardness observed from 120 to $150 \mathrm{~A}$ (56.8 to 51.3 HRC - Fig. 8) may be directly associated with a lack of a primary Laves phase (see Fig. 4 and Fig. 5). Further increase on dilution promotes hardness restoring (for 180 / 200 A - 54.9 / 58.5 HRC, respectively) since much more silicon and carbon are present. It is interesting to highlight that the eutectic morphology changed to harder skeletonlike carbides (see Figs. 6 and 7). Opposed to what has been previously observed regarding the effect of dilution with iron-base alloy substrates on the T400 alloy, in which a decrease in hardness was found ${ }^{24-26}$, the processing on highcarbon cast iron was able to maintain or even increase the high coatings hardness. 
From the nanoindentation tests, it can be noticed that labyrinth-like eutectics (120 and 150 A) presented a slight hardness increase from 7.1 and $7.7 \mathrm{GPa}$, respectively. Considering the higher eutectic hardness (for $150 \mathrm{~A}$ ), the effect of primary Laves suppression on the hardness Rockwell $\mathrm{C}$ is now even more evident. Further assessment on the skeleton-like eutectics presented hardness of approximately 9.3 - 9.4 GPa, which in turn explains the hardness restoring, observed for 180 and 200 A deposition currents. Additionally, primary Laves $(11.3 \mathrm{GPa})$ and primary carbides (from 14.7 to $21.5 \mathrm{GPa}$ ), as well as $(\mathrm{Co}, \mathrm{Fe})$-solid solution (4.2 to $5.0 \mathrm{GPa})$, exhibited coherent values of hardness. Although the contribution of each phase on coatings hardness is dependent on the phases volume fraction, it may be asserted with some confidence that, under the experimental conditions and ranges of dilution evaluated in this study, primary Laves controls the overall hardness for the lowest heat input (120 A), whereas eutectic carbides control it for higher ones.

Scratch tests also confirmed differences in the microstructure (seeFig. 13), as pointed out earlier by the hardness tests. In fact, an even more evident result is the width differences observed among the distinct phases comprising the microstructure. Even so, eutectic regions showed mean track width ranging between 7.0 and $7.5 \mu \mathrm{m}$ for 120 and $150 \mathrm{~A}$ (labyrinth-like) and between 6.2 and $6.5 \mu \mathrm{m}$ for 180 and 200 A (skeletonlike), respectively.

\section{Conclusions}

Microstructure and properties of CoCrMoSi alloy coatings processed on high-carbon ductile iron GGG40 were assessed. The following conclusions may be presented:

- Deposition on ductile iron (GGG 40) showed higher dilution - for the same heat input - comparing with processing on stainless steel substrate reported in previous works. Hence, dilution directly depends on the melting point of the chosen substrate.

- Laves phase reinforced alloys may be processed on ductile Iron GGG40 substrate with primary and secondary Laves phase, since enough amounts of silicon and molybdenum are present, i. e. dilution is lower than $26 \%$.

- Dilution higher than $41 \%$ is able to suppress either primary or secondary Laves phase, altering the hardening phases. Morphology is firstly labyrinth-like eutectic with carbides and, as the dilution increases, skeleton-like morphology takes place because of the introduced higher quantity of carbon and silicon.

- Coatings hardness is ruled by primary Laves for the lowest heat input. Departing from $150 \mathrm{~A}$, Laves phase suppression induces hardness decrease, whereas for a larger introduction of iron, silicon and carbon hardness restoring is observed due to harder skeleton-like eutectic carbides formation.
- Despite totally suppressing Laves phase from $150 \mathrm{~A}$ main current on, the hardness and scratch behavior of the coatings were positively influenced due to further dilution increase (180 and $200 \mathrm{~A})$. A strong case can be made that the in situ hard phases formed by the interaction with the substrate must be a key point for designing coatings that can withstand wear conditions.

\section{Acknowledgements}

The authors would like to thank AWARE (international cooperation agreement) for financial support. It enables a partnership between Technische Hochschule Ingolstadt (THI) and Federal University of Parana (UFPR).

The authors would also like to thank the Academic Publishing Advisory Center (Centro de Assessoria de Publicação Acadêmica, CAPA - www.capa.ufpr.br) of the Federal University of Parana (UFPR) for assistance with English language editing.

\section{References}

1. Venkatesh B, Sriker K, Prabhakar VSV. Wear Characteristics of Hardfacing Alloys: State-of-Art. Procedia Materials Science. 2015;10:527-532. DOI: https://doi.org/10.1016/j. mspro.2015.06.002

2. Burakowski T, Wierzschon T. Surface Engineering of Metals: Principles, Equipments, Technologies. Boca Raton: CRC Press; 1999.

3. Gonçalves e Silva RH, Dutra JC. PTA-P Process - A literature review as basis for innovations. Part 2 of 2: powder thermal and kinematic behavior, process parameters and consumables. Soldagem \& Inspeção. 2012;17(2):173-183. DOI: http://dx.doi. org/10.1590/S0104-92242012000200011

4. Díaz VV, Dutra JC, D'Oliveira ASC. Hardfacing by Plasma Transferred Arc Process. In: Sudnik W, ed. Arc Welding. Rijeka: InTech; 2011. DOI: 10.5772/28802

5. Cameron CB, Ferris, DP. Tribaloy Intermetallic Materials: New Wear-and Corrosion-Resistant Alloys. Anti-Corrosion Methods and Materials. 1975;22(4):5-8. DOI: https://doi.org/10.1108/ eb010165

6. Schmidt RD, Ferriss DP. New Materials Resistant to Wear and Corrosion to $1000^{\circ}$ C. Wear. 1975;32(3):279-289. DOI: https:// doi.org/10.1016/0043-1648(75)90316-6

7. Tavakoli A, Liu R, Wu XJ. Improved mechanical and tribological properties of tin-bronze journal bearing materials with newly developed tribaloy alloy additive. Materials Science and Engineering: A. 2008;489(1-2):389-402. DOI: https://doi. org/10.1016/j.msea.2007.12.030

8. Yao MX, Wu JBC, Liu R. Microstructural characteristics and corrosion resistance in molten $\mathrm{Zn}-\mathrm{Al}$ bath of CoMo-Cr-Si alloys. Materials Science and Engineering: $A$. 2005;407(1-2):299-305. DOI: https://doi.org/10.1016/j. msea.2005.07.054 
9. Xu W, Liu R, Patnaik PC, Yao MX, Wu XJ. Mechanical and tribological properties of newly developed tribaloy alloys. Materials Science and Engineering: A . 2007;452-453:427-436. DOI: https://doi.org/10.1016/j.msea.2006.10.088

10. Liu R, Xu W, Yao MX, Patnaik PC, Wu XJ. A newly developed Tribaloy alloy with increased ductility. Scripta Materialia. 2005;53(12):1351-1355. DOI: https://doi.org/10.1016/j. scriptamat.2005.08.033

11. Scheid A, de Oliveira ASCM. Analysis of PTA hardfacing with CoCrWC and CoCrMoSi alloys. Soldagem \& Inspeção. 2013;18(4):322-328. DOI: http://dx.doi.org/10.1590/S010492242013000400004

12. Przybylowicz J, Kusinski J. Laser cladding and erosive wear of CoCrMoSi coatings. Surface and Coatings Technology. 2000;125(1-3):13-18. DOI: https://doi.org/10.1016/S02578972(99)00563-0

13. Scheid A, D'Oliveira ASCM. Effect of processing on microstructure and properties of CoCrWC alloy. Materials Research. 2013;16(6):1325-1330. DOI: http://dx.doi.org/10.1590/ S1516-14392013005000120

14. Zhang K, Deng J, Meng R, Lei S, Yu X. Influence of laser substrate pretreatment on anti-adhesive wear properties of WC/Co-based TiAlN coatings against AISI 316 stainless steel. International Journal of Refractory Metals and Hard Materials. 2016;57:101-114. DOI: http://dx.doi.org/10.1016/j. ijrmhm.2016.03.004

15. Tobar MJ, Amado JM, Álvarez C, García A, Varela A, Yáñez A. Characteristics of Tribaloy T-800 and T-900 coatings on steel substrates by laser cladding. Surface and Coatings Technology. 2008;202(11):2297-2301. DOI: http://dx.doi.org/10.1016/j. surfcoat.2007.11.025

16. Navas C, Cadenas M, Cuetos JM, Damborenea J. Microstructure and sliding wear behavior of Tribaloy T-800 coatings deposited by laser cladding. Wear. 2006;260(7-8):838-846. DOI: http:// dx.doi.org/10.1016/j.wear.2005.04.020

17. Fernandes F, Lopes B, Cavaleiro A, Ramalho A, Loureiro A. Effect of arc current on microstructure and wear characteristics of a Ni-based coating deposited by PTA on gray cast iron. Surface and Coatings Technology. 2011;205(16):4094-4106. DOI: http://dx.doi.org/10.1016/j.surfcoat.2011.03.008

18. Fernandes F, Polcar T, Loureiro A, Cavaleiro A. Effect of the substrate dilution on the room and high temperature tribological behavior of Ni-based coatings deposited by PTA on grey cast iron. Surface and Coatings Technology. 2015;281:11-19. DOI: https://doi.org/10.1016/j.surfcoat.2015.09.034
19. Fernandes F, Ramalho A, Loureiro A, Cavaleiro A. Mapping the micro-abrasion resistance of a Ni-based coating deposited by PTA on gray cast iron. Wear. 2012;292-293:151-158. DOI: http://dx.doi.org/10.1016/j.wear.2012.05.018

20. Fernandes F, Cavaleiro A, Loureiro A. Oxidation behavior of Ni-based coatings deposited by PTA on gray cast iron. Surface and Coatings Technology. 2012;207:196-203. DOI: http:// dx.doi.org/10.1016/j.surfcoat.2012.06.070

21. Shi $\mathrm{K}, \mathrm{Hu} \mathrm{S}$, Zheng $\mathrm{H}$. Microstructure and fatigue properties of plasma transferred arc alloying TiC-W-Cr on gray cast iron. Surface and Coatings Technology. 2011;206(6):1211-1217. DOI: https://doi.org/10.1016/j.surfcoat.2011.08.034

22. Gallo SC, Alam N, O\&apos;Donnell R. In-situ precipitation of TiC upon PTA hardfacing with gray cast iron and titanium for enhanced wear resistance. Surface and Coatings Technology. 2013;214:63-68. DOI: https://doi.org/10.1016/j.surfcoat.2012.11.003

23. Halstead A, Rawlings RD. The effect of iron additions on the microstructure and properties of the "Tribaloy" Co-Mo$\mathrm{Cr}-\mathrm{Si}$ wear resistant alloys. Journal of Materials Science. 1985;20(5):1693-1704.

24. Bohatch RG, Athayde JN, Siqueira JCM, D'Oliveira ASCM, Scheid A. Influence of Processing on the Microstructure and Properties of CoCrMoSi Alloy PTA Coatings. Soldagem \& Inspeção. 2015;20(2):219-227. DOI: http://dx.doi.org/10.1590/0104-9224/ SI2002.09

25. Bohatch RG, Graf K, Scheid A. Effect of Track Overlap on the Microstructure and Properties of the CoCrMoSi PTA Coatings. Materials Research. 2015;18(3):553-562. DOI: http://dx.doi. org/10.1590/1516-1439.340014

26. Paes RMGP, Scheid A. Effect of deposition current on microstructure and properties of CoCrWC alloy PTA coatings. Soldagem \& Inspeção. 2014;19(3):247-254. DOI: http://dx.doi org/10.1590/0104-9224/SI1903.07

27. Ferreira LS, Graf K, Scheid A. Microstructure and Properties of Nickel-based C276 Alloy Coatings by PTA on AISI 316L and API 5L X70 Steel Substrates. Materials Research. 2015;18(1):212221. DOI: http://dx.doi.org/10.1590/1516-1439.332914

28. Antoszczyszyn TJ, Paes RMG, de Oliveira ASCM, Scheid A. Impact of dilution on the microstructure and properties of Ni-based 625 alloy coatings. Soldagem \& Inspeção. 2014;19(2):134-144. DOI: http://dx.doi.org/10.1590/0104-9224/SI1902.05

29. Jiang L, Zhang WZ, Xu ZF, Huang HF, Ye XX, Leng B, et al. M2C and M6C carbide precipitation in Ni-Mo-Cr based superalloys containing silicon. Materials \& Design. 2016;112:300-308. DOI: http://dx.doi.org/10.1016/j.matdes.2016.09.075 